\title{
Urban modal shift management in cities: an indicator based approach
}

\author{
L. Vermote \& L. Hens \\ Department of Human Ecology, Vrije Universiteit Brussel, Belgium
}

\begin{abstract}
Increased transport has negative effects on quality of life, welfare and environment, especially in urban areas. Despite the indispensable function of transport in society, reflections on its overall sustainability must be considered. Minimizing congestion and emissions restricts environmental damage, air pollution, noise nuisance and loss of productive time. In composing sustainable transport policy, city authorities should rely on an assessment monitor to direct transportation patterns towards an urban modal shift. This paper proposes a methodology to assess urban transport, based on sustainability indicators. Different ecological, social, economical and transport indicators are presented to measure current urban transportation patterns. The integration of such assessment instruments in urban modal shift management should improve accessibility and quality of life.
\end{abstract}

Keywords: urban transport, sustainability indicators, modal shift management.

\section{Introduction}

How can the state of the urban modal shift be assessed? Which methodology is required? This paper proposes a methodology for the development of a monitor to assess the sustainability of transportation patterns. Local authorities can call on a suggested indicator set, containing four themes and eight domains, to direct urban transport towards a modal shift. How can a suitable methodology be developed for monitoring the sustainability of urban transport? Determinations of the basic concepts of our methodology treat the origin of sustainable development and how it is completed. Further, perspectives for the assessment instrument are suggested. Which point of view is integrated, why call for assessment and which conditions must be fulfilled? Finally, an indicator set is 
derived out of the basic assumptions to monitor urban shift management, which is structured according to two classifications.

\section{Materials and methods}

The methodology to construct the monitor is based on an explorative literature study. In composing the methodology, the assessment instrument for sustainable agriculture and horticulture of Mulier et al. [21] influenced our approach. Perspectives for rural planning from Bosshard [6] and the methodology for evaluating sustainable farming from Andreoli et al. [1, 2] were also considered. When applying the frame on transport issues and selecting sustainable transport indicators, the work of Litman [17]; Hecq et al. [13] and Moles et al. [20] gave additional value. Once the methodology is completely established, the assessment monitor can be applied in similar European cities, picturing to which extend an urban modal shift is developed.

The first step in our methodology elaborates the content of the important concepts. Then, the sustainability of individual motorised transportation patterns is discussed, leading to the definition of sustainable transport. Because sustainable transport is extended in application on policy level, refining is necessary. Policy development concerning sustainable transportation is restricted to urban modal shift management. Air transport falls outside the concept determination.

After the conceptual framework, the perspective of the monitor is elaborated. Four key themes are derived out of the perspective. Ecology, economy, social aspects and transport are the assessment themes for sustainable transport, which are each individually divided into two domains. These themes and domains link the indicators to the object of the monitor

Eight sets of indicators are selected for every domain and structure each theme into four tables. The tables show to what extent an indicator is considered as a driving force, pressure, state, impact or response. This DPSIR model helps qualifying the indicators before integrating them into policy development.

\section{Results}

\subsection{Conceptual framework}

\subsubsection{Sustainable development}

The sustainable development concept emerged in the early and mid 1980s out of a particular historical context, which contested climate change discourses and development. Concepts like sustainable society, under-development and overdevelopment formalized sustainable development. This theoretical construction attempts to bridge the gap between environmental concerns about ecological consequences of human activities and socio-political concerns about human development issues (Robinson [23]). The World Commission on Environment and Development (Brundtland Commission) demarcated the concept for one of the first times, in 1987. From that day on, sustainable development became a 
central discourse in environment and development. This first definition is broadly formulated:

"Sustainable development can be considered as a development that meets the needs of the present generation without compromising the ability of future generations to meet their own needs" (WCED [28])

Development that doesn't jeopardize the ecological, socio and economic potential of future generations is the essential feature. The Brundtland definition integrated this social aspect in the principle of sustainable development. All following sustainable development discussions quote the synergy between ecological - economical - and social aspects of development.

Sustainable development refers to the contradiction between growth and development at the one hand side and ecological, economical and social sustainability at the other side (Robinson [23]). The application of sustainable development must reconcile the ecological consequences of human activities with socio-political ideas about development. Harmonisation of ecological, economical and social interests is the final objective.

The trilogy human - prosperity - environment founds the concept of sustainable development. An established balance between ecological, economical and social interests must generate societal development, without impeding future generations.

\subsubsection{Transport's impact on society}

\subsubsection{Ecological impact}

Climate change

Transport discharges almost $30 \%$ of total $\mathrm{CO}_{2}$ emissions in OECD countries (IEA, 2007). In other countries, the average is estimated at 23\%. Without reductive measures, $\mathrm{CO}_{2}$ emissions will increase with $120 \%$ by 2050 . With $84 \%$ of the $\mathrm{CO}_{2}$ emissions, road transport is the main contributor of all transportation patterns within the European Union (Hens [14]). Additional $\mathrm{CO}_{2}$ emissions, caused by human activity, accelerate the natural greenhouse effect. Climate change can lead to extreme weather conditions, air pollution, rise in sea level, degrading drinking water quality, desertification, spread of diseases and destruction of biodiversity (Beniston [4]).

\section{Air pollution}

Contemporary transportation patterns are responsible for the emissions of small particles, $\mathrm{NO}_{\mathrm{X}}$ (nitrogen oxides) and other gaseous substances. Inhalation of such substances leads to increasing mortality and hospitalizations, due to respiratory and cardiovascular affections (Hens [14]). Small particles, mainly emitted by diesel engines, require special attention. Research in France, Austria and Switzerland studied the impact of small particles on the public health. About 20.000 deaths a year can be assigned to transport. Transport emissions are furthermore responsible for more than 25.000 new chronic bronchitis cases 
among adults, 290.000 bronchitis cases among children and 500.000 asthma attacks (Künzli et al. [16]).

\section{Depletion of resources}

The energy required to build a car, is equal to the amount of energy a car consumes during his lifetime. Each individual car is responsible for 25 ton of waste, compared to 1 ton of its mass. Increasing use of plastic and electronics makes it even more difficult to recycle cars (Hens [14]; OECD [22]). Transport is responsible for $30 \%$ of all energy consumption and about $71 \%$ of the total oil consumption in the European Union. About $60 \%$ of the transport oil consumption is used for road transport (European Commission [9]).

\section{Land use}

Construction of roads and parking lots occupies huge amounts of land. An average $25-35 \%$ of city space is used for roads. Approximately half of the available city space is used for vehicles, if parking spots and similar places are included. (Hens [14]; OECD [22]; Gudmundsson and Höjer [12]). Up to 28.949 $\mathrm{km}^{2}$ of the European territory was occupied by the road network, in 1986, which represents $1.3 \%$ of total territory of the Union. Intersections, crossing and parking lots were not included (Hecq et al. [13]).

\subsubsection{Social impact}

\section{Health effects}

Transport has a significant impact on the human health. Air pollution causes a large range of health related problems, varying from eye irritations to hospitalisation and increased mortality (see supra). Beside this, transport is responsible for noise nuisance. Road traffic is the most important source of noise nuisance in urban regions, or near highways. Noise nuisance can cause loss of hearing, hypertension, ischemia, annoyance, sleep disturbances, impaired performance and mood modifications (Hens [14]).

\section{Traffic unsafety}

Traffic accidents cause more than 1,2 million deaths and 50 million injuries worldwide every year. About 120.00 deaths and 2,5 million injuries result from traffic casualties in Europe (WHO [29]). Pedestrians and cyclists are most vulnerable in this context (Hens [14]). Predictions state that the amount of casualties will decrease in the West between 2000 and 2020 by 30\%. About $85 \%$ of all traffic fatalities occur in developing countries (WHO [29]).

\section{Social exclusion}

Individual motorised transport is regarded as elitist and undemocratic. More than $40 \%$ of European households have no car (European Commission [10]), while the contemporary transportation system ignores the needs of children, youngsters, elderly and disabled. These groups have equal rights to individual access and transportation (Bilbao-Ubillos [5]). 


\subsubsection{Economic impact}

\section{Traffic jams and congestion}

Traffic jams leads to economical loss, caused by unproductive time and increasing transportation costs. Costs of fuel consumption, traffic accidents and negative impact on local economical activities in cities are other ecological consequences of congestion (Bilbao-Ubillos [5]). The European economy loses about $€ 100$ billion on yearly basis (European Commission [10]).

\section{Increasing fuel prices}

Since the transport sector relies for $98 \%$ on oil, fuel prices are very sensitive within the sector (European Commission [9]). Oil demand in booming development economies, like China, reinforce price fluctuation. The share of transport in the national oil consumption is quite high in such countries. Energy supply may be threatened in both highly-motorised countries and developing motorised countries (Banister [3]).

\subsection{3 'Sustainable transport'}

Individual motorised patterns of transportation are not sustainable. Sustainable transport should be well defined to construct an assessment monitor. In relation to the Brundtland definition, sustainable transport can be defined as 'transport that meets the needs of the present without compromising the ability of future generations to meet their own needs' (Tolley [25]). This curtailed definition is obsolete for assessing the sustainability of contemporary transport patterns.

The societal pillars of sustainable development must be integrated in the sustainable transport determination. There is no common accepted definition of sustainable transport, although it is generally accepted that the path to sustainable transport implies a proper balance between (current and future) environmental, social and economic qualities (Steg and Gifford [24]). Compared to the first definition, the latter one stresses the integration of the three sustainability pillars.

Western nations gave special attention to sustainability of land use and transportation patterns. In this context, sustainable transportation is seen as transportation that meets mobility needs, while also preserving and enhancing human and ecosystem health, economic progress and social justice now and for the future (Deakin [7]). This definition can be seen as an improvement of the former two, as it combines the most important elements. Current and future preservation is quoted, while the three pillars are specified.

Because our concept of sustainable transport forms the base of an assessment monitor, special attention goes to its implementation on policy level. Sustainable decision-making can be described as planning that considers goals and impacts, regardless of how difficult they are to measure (Litman and Burwell [18]). Decision-making on sustainable transport implies the construction of a comprehensive measurement tool, which directs transport towards sustainability.

Sustainable transport is an aspect of sustainable development. Developments, responding to the increasing demand in transportation, must reconcile ecological, economic and social interests, preserving present and future generations. Extra 
emphasis is put on the integration of sustainable transportation in the decisionmaking process, regarding the goal of this study. Policy development should consider long-term planning, by measuring the impact of transport patterns.

\subsubsection{Towards 'urban modal shift management'}

Regarding the scope of sustainable transport, reflections on its practical application must be made. Which template of sustainable transport makes our urban assessment monitor the most effective? This study refines sustainable transport, by introducing the principle of 'urban modal shift management'. A modal shift is defined as a displacement of road transport towards other transport modes that constitute 'intermodal transport', such as rail, inland waterways and maritime transport (Tsamboulas et al. [27]). Intermodal transport is defined as the combination of at least two modes of transport in a single transport chain (Macharis and Pekin [19]).

The modal shift is a substantial part of sustainable transport. Displacement towards intermodal transport concerns both freight - and passenger transport. Freight transport is the most common type of intermodal transport on macro level. Passenger and freight transport take an equal share on the meso level, as passenger transport is the most established intermodal transport type on micro level.

Modal shift management refers to the guiding and steering of road transport towards intermodal transport, while influencing attitude and behaviour of road users. Reducing individual motorised transport, by converting vehicle use to alternative transportation modes, is the final object of modal shift management. Modal shift management can be seen as a sub-category of mobility management. Until the early 1990s, mobility management dealt with the negative impacts of transport by large-scale infrastructural investments. Recently it is committed to promote modal shift and alternatives to travel (Gronau and Kagermeier [11]). The discipline intends to manage the mobility needs of the people, but ignores the balance between the three sustainability pillars. Because ongoing investments in individual motorised transport are considered as less sustainable, modal shift management is more applicable in the assessment monitor than mobility management.

Steering modal shift can be accomplished at different levels. European modal shift management focuses on the major freight flows between economic core regions and seaports. These should be transformed to rail - and inland waterway transport patterns. National or regional modal shift management aims at displacing freight and people to intermodal transportation patterns within certain regions. Inter-urban and regional connections are the study object.

This paper gives urban modal shift management a central place in the sustainable transport policy of local authorities. Passenger transport gets special attention in this context, because cities offer a wide range of alternatives to individual motorised patterns of transport. Public transport, cycling and walking are the most common illustrations. Urban freight transport encounters a problem in relation to the local modal shift. Intermodal transport cannot compete with unimodal truck service over distances less than $400 \mathrm{~km}$ (Trip and Bontekoning 
[26]; Machris and Pekin [19]). Solutions must be found in the potential of urban distribution terminals. Urban modal shift management is the starting point of the assessment monitor.

\subsection{Perspectives}

After formulating the conceptual framework, the monitor demands a clear point of view. Some methodologies use reductionist views, which lead to increasing specialisation and deepening knowledge on specific topics. Such research interventions are regarded as unidimensional (Andreoli and Tellarini [2]). Our assessment tool starts from a holistic point of view to study the different phenomena. All relevant aspects are taken into account. Sustainable transport policy must cope with multidimensional problems (Andreoli et al. [1]).

Subsequently, the question is why call for an assessment? Our monitor must assess transport in cities. Contemporary transport patterns cause negative effects in different segments of society. By integrating the monitor in urban modal shift management, local authorities can direct the transportation policy towards sustainability. Restoring the balance between ecological, economic and social interests by guaranteeing a sustainable transportation system is the final objective of the assessment.

Furthermore, the monitor must accomplish certain conditions. It is important that both strengths and weaknesses of sustainability are detected. The tool should be sufficiently relevant and understandable (Mulier et al. [21]). While transferring the assessed issues to policymakers, the instrument must be communicatively strong in function of time and costs. Comparing the situation in similar cities is an additional condition that must be accomplished by the monitor.

\subsection{Sustainability themes}

Based on our perspective, decisive themes are selected for assessing sustainable transport. The different themes can be defined as particular viewpoints, each related to a goal (Bosshard [6]). Four general themes found our monitor. The themes ecological-, economical-, social- and transport aspects are used for the assessment and measurement of sustainable transport, each with an equal proportion and weight. These four themes are most suitable for our research design, in relation to our founding trilogy human - prosperity - environment, the three societal impacts of transport, our holistic vision and application object of the monitor. The first three themes compose general aspects of sustainable development, related to transport. An additional holistic/specific dimension must measure the urban transport state. The four sustainability themes are subdivided into eight different domains. First of all, economy is split into "costs" and "efficiency". Costs as a domain, composes the economic costs of current motorized transportation patterns to society as a whole and/or to individual road users. Efficiency on the other hand, renders the effectiveness of economical transportation compounds. 
A division into "quality of life" and "user preferences" is made for the social theme. Impact of individual motorized transport on the health of urban dwellers and the livability of their environment, is merged in the domain quality of life. User preferences are the second social domain, which expresses the satisfaction of users and specific user groups, in relation to different transport modes.

Ecology is divided into the domains "ecosystem" and "use of ecological potential". Pressure of individual motorized transport on diverse aspects of the ecosystem, appear under the ecosystem domain. Use of ecological potential addresses how current transportation patterns rely on the available ecological potential.

"Transport activities" and "vehicle alternatives" are the two last domains, which are derived from the theme transport. Because our monitor wants to assess the sustainability of urban transport patterns, general aspects of transport activities should be integrated. Next to measuring sustainability, our assessment tool should be used to direct urban transport towards the modal shift. Different alternatives for the usage of vehicles in urban areas must be measured in this regard.

\subsection{Selecting indicators}

Indicators compose the central part of the assessment monitor. The three major functions of indicators are quantifying information, simplifying information and improving communication (Hecq et al. [13]).

Table 1: $\quad$ Social indicators, structured by domain and DPSIR.

\begin{tabular}{|c|c|c|}
\hline Indicator & Domain & DPSIR \\
\hline Different polluting emissions & Quality of life & P \\
\hline $\begin{array}{c}\text { Pollutant in excess of EU air quality } \\
\text { standards }\end{array}$ & Quality of life & P \\
\hline Noise nuisance & Quality of life & I \\
\hline Casualties per mode & Quality of life & I \\
\hline Victims per mode & Quality of life & I \\
\hline Fitness of road users & Quality of life & I \\
\hline Community livability & Quality of life & I \\
\hline City green & Quality of life & I \\
\hline Car free area's & Quality of life & S \\
\hline Zone 50 area's and zone 30 area's & Quality of life & S \\
\hline Affordability per mode & Quality of life & DF \\
\hline Rating of vehicle usage & User preferences & S \\
\hline Rating of Urban Public Transport usage & User preferences & S \\
\hline Rating of U.P.T. usage by elderly & User preferences & S \\
\hline Rating of U.P.T. usage by disabled people & User preferences & S \\
\hline Children to school travel & User preferences & S \\
\hline Company transport plan & User preferences & S \\
\hline Children collecting plan & User preferences & S \\
\hline
\end{tabular}


An indicator is an interface that measures a certain phenomenon, in order to evaluate progress towards goals and objectives. Indicators must be carefully selected to provide useful information. In most situations, a single indicator is not adequate, so a set of indicators is instead selected. Policy makers who use the indicators must understand their perspectives and limitations. Eventually, it is desirable that the selected data of the indicator is suitable for comparison with other jurisdictions and organisations (Litman [17]).

Our assessment monitor is based on four core themes, which are subdivided into eight domains. Four tables give an overview of the indicator sets for each theme and their two related domains. The tables structure the different indicators as driving force, pressure, state, impact or response. This DPSIR framework serves as a structure to present needed indicators for policy development. The frame reveals a chain of causal links between the indicators. 'Driving forces' (economic sectors, human activities) create 'pressures' (emissions, waste) that lead to 'states' (physical, chemical and biological), impacts on ecosystems and human health, resulting in political 'responses' (prioritization and target setting) (Kristensen [15]).

The first table shows possible indicators for quality of life and user preferences. All emissions are considered as pressures of the driving force transport. Other indicators for quality of life are direct impacts of the transportation system. Different indicators for areas and all indicators for user preferences are states of the environment. Affordability per mode is a driving force because it is considered as a need varying to economic levels of households.

Table 2: $\quad$ Economic indicators, structured by domain and DPSIR.

\begin{tabular}{|c|c|c|}
\hline Indicator & Domain & DPSIR \\
\hline Crash costs & Costs & I \\
\hline Congestion delay passenger & Costs & I \\
\hline Congestion delay freight & Costs & I \\
\hline Congestion travel costs & Costs & I \\
\hline Transport facility costs & Costs & I \\
\hline Households with 2 or more cars & Costs & I \\
\hline Expenses per transport mode & Costs & DF \\
\hline Freight efficiency & Economic efficiency & I \\
\hline Delivery services efficiency & Economic efficiency & I \\
\hline Pricing reforms & Economic efficiency & I \\
\hline Transport revenue related to expenses & Economic efficiency & I \\
\hline Transportation costs efficiency & Economic efficiency & I \\
\hline
\end{tabular}

The second table presents possible indicators for costs and economic efficiency. All indicators for economic costs and economic efficiency are considered as an impact of the transportation system. They change the welfare of human beings. Except expenses per transport modes is an individual driving force, related to the economical situation of households. 
Table 3: $\quad$ Ecologic indicators, structured by domain and DPSIR.

\begin{tabular}{|c|c|c|}
\hline Indicator & Domain & DPSIR \\
\hline $\mathrm{CO}_{2}$ emissions & Ecosystem & $\mathrm{I}$ \\
\hline Water pollution & Ecosystem & $\mathrm{I}$ \\
\hline Habitat protection & Ecosystem & $\mathrm{I}$ \\
\hline Habitat fragmentation & Ecosystem & $\mathrm{I}$ \\
\hline Impact roads on land use & Use of ecological potential & $\mathrm{I}$ \\
\hline Impact parking lots on land use & Use of ecological potential & $\mathrm{I}$ \\
\hline City green & Use of ecological potential & $\mathrm{I}$ \\
\hline Resource use & Use of ecological potential & $\mathrm{I}$ \\
\hline
\end{tabular}

Table 4: $\quad$ Transport indicators, structured by domain and DPSIR rate.

\begin{tabular}{|c|c|c|}
\hline Indicator & Domain & DPSIR \\
\hline Dwellers working in city & Transport activities & DF \\
\hline Commuters going out of city & Transport activities & DF \\
\hline Commuters coming in city & Transport activities & DF \\
\hline Travelling to work per transportation mode & Transport activities & DF \\
\hline Commuting trends & Transport activities & DF \\
\hline Total transport volume per mode & Transport activities & DF \\
\hline Amount of freight coming in city per mode & Transport activities & DF \\
\hline Occupancy of different transport modes & Transport activities & DF \\
\hline Presence of urban freight distribution & Transport alternatives & $\mathrm{R}$ \\
\hline terminals & & \\
\hline Implementation of information campaigns & Transport alternatives & $\mathrm{R}$ \\
\hline Offer and quality U.P.T. infrastructure & Transport alternatives & $\mathrm{R}$ \\
\hline U.P.T coverage and efficiency & Transport alternatives & $\mathrm{R}$ \\
\hline Offer and quality N.M.T. infrastructure & Transport alternatives & $\mathrm{R}$ \\
\hline Offer and quality inland waterway & Transport alternatives & $\mathrm{R}$ \\
infrastructure & & $\mathrm{R}$ \\
\hline Offer and quality port infrastructure & Transport alternatives & $\mathrm{R}$ \\
\hline Park and Ride facilities & Transport alternatives & $\mathrm{R}$ \\
\hline Bike and Ride facilities & Transport alternatives & $\mathrm{R}$ \\
\hline Amount of U.P.T. permit users & Transport alternatives & $\mathrm{R}$ \\
\hline Care share facilities & Transport alternatives & $\mathrm{R}$ \\
\hline Car pool associations & Transport alternatives & $\mathrm{R}$ \\
\hline Car free zone & Transport alternatives & $\mathrm{R}$ \\
\hline Zone 50 area's and zone 30 area's & Transport alternatives & $\mathrm{R}$ \\
\hline
\end{tabular}

The third table suggests indicators for ecosystem and usage of ecological potential. All ecological indicators are impacts of the driving force transport, determining the quality of the ecosystem

Table four presents indicators for transport activities and transport alternatives. All transport activities are regarded as driving forces because they are needs. Transportation needs are secondary driving forces. Indicators for transport alternatives are responses. They will measure to what extend the society or policy makers respond to the undesired impacts of transport. 


\section{Discussion}

The suggested methodology wants to measure the state of the urban modal shift. The four themes and eight domains are a first attempt in structuring theoretical sustainability frames towards indicators for practical application. Regarding the object of the monitor, the selection of four core themes like ecology, economy, social and transport was an obvious starting point. Adding an additional theme is possible, but maybe not appropriate. Adding another domain on the other hand, is open for discussion and suggestions. The transport theme in particular, can be subdivided and structured in differently.

The DPSIR framework, classifying the indicators in the five groups: driving force, pressure, state, impact and response, provides a second structure. This classification enables policymakers to get an idea, to what extend they can really influence the measured situation. The labelling and classification of the different indicators, is open for discussion as well. The indicator "zone 50 area's" for example, is classified as state in the social theme, but as response according to the transport theme.

Future steps will link the different indicators to suitable measure criteria and appropriate data. Aggregation of the monitor will be the final step.

\section{References}

[1] Andreoli, M., Rossi, R. \& Tellarini, V., Farm sustainability assessment: some procedural issues. Landscape and Urban Planning, 46, pp. 41-50, 1999.

[2] Andreoli, M. \& Tellarini, V. Farm sustainability evaluation: methodology and practice. Agriculture, Ecosystem and Environment, 77, 43-52, 2000.

[3] Banister, D., Unsustainable transport, Routledge: London, 2005.

[4] Beniston, M., Sustainable urban development and transport - a Eurovision for 2020. Transport Reviews, 20(1), pp. 113-130, 2002.

[5] Bilbao-Ubillos, J., The cost of urban congestion: estimations of welfare losses arising from congestion on cross-town link roads. Transportation Research Part A, 42, pp. 1096-108, 2008.

[6] Bosshard, A., A methodology and terminology of sustainability assessment and its perspectives for rural planning. Agriculture, Ecosystem and Environment, 77, pp. 29-41, 2000.

[7] Deakin, E., Sustainable Development and Sustainable Transportation, Strategies for Economic Prosperity, Environmental Quality and Equity. Working Paper, Institute of Urban and Regional Development, University of California at Berkeley. 2003

[8] European Commission, Europa duurzaam in beweging. Duurzame mobiliteit voor ons continent._Bureau voor officiële publicaties der Europese gemeenschap: Luxemburg, 2006. 
[9] European Commission Klimaatsverandering. Commissie stelt voor om luchtvervoer op te nemen in de EU-regeling voor de handel in emissierechten, Brussel, 2006.

[10] European Commission, Groenboek. Een nieuwe stedelijke mobiliteitscultuur. Brussel 2007.

[11] Gronau, W. \& Kagermeier, A., Mobility management outside metropolitan areas: case study evidence from North Rhine - Westphalia. Journal of Transport Geography, 12, pp. 315-322, 2004

[12] Gudmundsson, H. \& Höjer, M., Sustainable development principles and their implications for transport. Ecological Economics, 19, pp. 269-282, 1996.

[13] Hecq, W., De Villers, J., Reniers, J.M. \& Bauler, T., Elaboration et application d'un set d'indicateurs pour un development durable des transports en Belgique, Centre d'Etudes Economiques et Sociales de l'Environment (CEESE), Université Libre de Bruxelles, 2001.

[14] Hens, L., Mobility and transport in the Johannesburg Plan of Implementation and national environmental action plans. In: Nicolopoulou-Stamati, P., Hens, L. and Howard, C.V. (Ed.) Environmental Health Impacts of Transport and Mobility. Springer: Dordrecht, 2005.

[15] Kristensen, P., The DPSIR Framework, National Environmental Research Institute, Denmark, 2004.

[16] Künzli, N. et al., Public-health impact of outdoor traffic-related air pollution: a European assessment. Lancet, 356, pp. 795-801, 2000.

[17] Litman, T., Well Measured. Developing indicators for comprehensive and sustainable transport planning. Victoria Transport Policy Institute, Victoria, Canada, 2005.

[18] Litman, T. \& Burwell, D., Issues in sustainable transportation. International Journal for Global Environmental Issues 6, pp. 331-347, 2006.

[19] Macharis, C. \& Pekin, E., Assessing policy measures for the stimulation of intermodal transport: a GIS-based policy analysis._Journal of Transport Geography, available online 17 December 2008.

[20] Moles, R., Foley, W., Morrissey, J. \& O’Regan, B., Practical appraisal of sustainable development - Methodologies for sustainability measurement at settlement level. Environmental Impact Assessment Review, 28, pp. 144-165, 2008.

[21] Mulier A., Nevens F., Reheul D. \& Mathijs E., Ontwikkeling van een beoordelingssyteem voor de duurzaamheid van de Vlaamse land-en tuinbouw op bedrijfsniveau. Steunpunt Duurzame Landbouw, Publicatie 9, 2004.

[22] OECD, OECD Proceedings, towards sustainable transportation. The Vancouver Conference. Organisation for Economical Cooperation and Development, Paris, 1997.

[23] Robinson, J., Squaring the circle? Some thoughts on the idea of sustainable development. Ecological Economics, 48, pp. 369-384, 2004. 
[24] Steg, L. \& Gifford, R., Sustainable transportation and quality of life. Journal of Transport Geography 13, pp. 59-69, 2005.

[25] Tolley R. (Ed.) Sustainable Transport. Planning for walking and cycling in urban environments. Woodhead Publishing: Cambridge, 2000.

[26] Trip, J.J \& Bontekoning, Y., Integration of small freight flows in the intermodal transport system. Journal of Transport Geography, 10, pp. 221-229, 2002.

[27] Tsamboulas, D., Vrenken, H. \& Lekka, A.M., Assessment of a transport policy potential for intermodal mode shift on a European scale. Transport Research Part A, 41, pp. 715-733, 2007.

[28] WCDE - World Commission on Environment and Development, Our Common Future. Oxford University Press: Oxford, 1987.

[29] WHO, World report on road traffic injury prevention: summary. World Health Organisation, Geneva, 2004. 